\title{
Recent Advances in the Application of Stable Isotope Ratio Analysis in Forensic Chemistry
}

\author{
Niamh Nic Daeid,A,B Hilary A. S. Buchanan, A Kathleen A. Savage,A \\ James G. Fraser,A and Sarah L. CresswellA \\ ACentre for Forensic Science, Department of Pure and Applied Chemistry, \\ University of Strathclyde, Glasgow, G1 1XW, UK. \\ BCorresponding author. Email: n.nicdaeid@strath.ac.uk
}

This review paper updates the previous literature in relation to the continued and developing use of stable isotope ratio analysis in samples which are relevant to forensic science. Recent advances in the analysis of drug samples, explosive materials, and samples derived from human and animal samples are discussed. The paper also aims to put the use of isotope ratio mass spectrometry into a forensic context and discuss its evidential potential.

\section{Introduction}

Over the past half century we have seen enormous developments in science and scientific instrumentation applied to forensic analysis. The dominance of DNA since the late 1980 s is obvious, and we often forget that the past 50 years also saw fundamental developments in chemical analysis within forensic practice. The development of forensic applications for gas chromatography flame ionisation detection, gas chromatography-mass spectrometry (GC-MS), Fourier transform infrared spectroscopy (FTIR), Raman and, more recently, isotope ratio mass spectrometry (IRMS), have had a huge impact on what is now achievable within the forensic chemistry laboratory.

The casework encountered by forensic chemists has not changed over time, however, the volume of some types of cases have. Most forensic laboratories will engage in drug analysis, forensic toxicology, suspected arson cases, and 'criminalistics' of one type or another (glass, paint, fibres, footwear, etc.) as well as questioned document examination and cases relating to terrorism. Most laboratories will use chromatographic techniques as standard for the identification and quantification of explosives, drugs and drug metabolites and will make regular use of a variety of spectroscopic techniques as well. There is now a robust and rich literature developing on all aspects of forensic chemical analysis using these types of analytical methodologies.

In this review, therefore, we have decided to concentrate our comments on a relatively new (to forensic science) analytical technique. Stable IRMS has begun to emerge into the area of forensic chemistry and, in particular, its application in the analysis of illicit substances and explosives. It is not the intention of this review to present a fundamental explanation of IRMS as a technique, as this information is available elsewhere in the literature; however, this paper offers a review and commentary on the emerging use of this technique and updates the previous literature on this topic.[1-3]

\section{IRMS of Illicit Drugs}

In the past few decades, IRMS has been applied to both licit and illicit drugs for the purposes of determining geographic origin and/or discriminating between batches or manufacturer. While the results have been continually promising for this technique, data is at times limited due to the difficulty of obtaining a sufficient number of samples of known history.[4] For instance, IRMS is often applied to seized samples of unknown origin for the purpose of dividing the samples into isotopically similar groups. 
The implications of such an achievement, while potentially significant for forensic science, must be interpreted cautiously if the history of the samples is unknown.

In 1991, Desage et al.[5] attempted to determine the geographic origin of heroin by analyzing samples from various geographical regions. They were able to distinguish Turkish heroin from all other samples by analyzing the ${ }_{13} \mathrm{C}$ enrichment of the heroin (diamorphine) molecule. They could not, however, discriminate between heroin originating in Pakistan, Niger, and Thailand. In 1995, Mas et al.[6] used IRMS to analyze 16MDMA tablets seized between 1989 and 1992 and the tablets could be visually separated into four groups based on $\delta{ }_{13} \mathrm{C}$ values. By measuring $\delta 15 \mathrm{~N}$ enrichment of several of the 16 samples, Mas et al. showed that further discrimination was possible with $\delta 15 \mathrm{~N}$ values.A few years later, Besacier et al.[7] published a three-step approach to heroin profiling where the third step recommended isotope abundance analysis by IRMS.

In 2000, Nature published a study by Ehleringer et al.,[8] which demonstrated that the origin of cocaine could be correctly identified on the basis of $\delta 13 \mathrm{C}$ and $\delta 15 \mathrm{~N}$ values combined with the content of trace alkaloids truxillane and trimethoxycocaine in cocaine. The authors collected 200 coca leaf samples from five regions in South America and extracted cocaine. Analysis as described allowed identification of the correct geographic origin of the cocaine in $96 \%$ of the cases. In 2002, Carter et al.[9] confirmed the 1995 work of Mas et al.,[6] which revealed that $\mathrm{N}$ isotope analysis presented more discriminating power than $\mathrm{C}$ isotope analysis alone. They also went one step further and included $\mathrm{H}$ isotope analysis in the study. Fifty 'ecstasy' tablets were analyzed, 10 from each of five police seizures. The 10 tablets from a single seizure were assumed to be from the same batch; thus, isotopic analysiswas tested to see if it could separate the 50 tablets into five batches.

$\delta 13 \mathrm{C}$ values allowed the tablets to be separated into three groups, $\delta 15 \mathrm{~N}$ values allowed separation into five groups, and $\delta_{2} \mathrm{H}$ values allowed separation of only one of the five groups (i.e. separation into two groups).

Carter et al.[10] also investigated isotopic fractionation of amphetamines during synthesis. First, they attempted to identify sources of $\delta 13 \mathrm{C}$ and $\delta 15 \mathrm{~N}$ observed in illicit amphetamines by investigating the synthesis of methamphetamine. Synthesis of the amine from the corresponding ketone was performed with two different batches of methylamine; $\delta 15 \mathrm{~N}$ values for the two batches of methylamine reagent showed them to be isotopically distinct by $\sim 1.4 \%$. Once synthesized, however, the resulting methamphetamines had $\delta 15 \mathrm{~N}$ values between +9.2 and $-0.3 \%$. The authors concluded that because methylamine is the only source of nitrogen in the product, the variation in $15 \mathrm{~N}$ enrichment in the products could not be explained by variation in the precursor methylamine, but instead must be the result of fractionation due to conditions during the synthesis. Given that the syntheses were performed simultaneously with identical apparatus and reagents (apart from methylamine, which was being investigated), they also noted that the differences in $\delta 15 \mathrm{~N}$ values of the products were remarkable and must be the result of differences in rate of reagent addition and resulting reaction temperature. In the second part of this study, Carter investigated IRMS analysis of chemically degraded samples of methylenedioxymethylamphetamine (MDMA). In this instance, MDMA

was isolated and purified from four ecstasy tablets and then oxidized back to the corresponding ketone and aldehyde. For three of these samples, no significant difference was found between the $\delta{ }_{13} \mathrm{C}$ values of the corresponding ketone and aldehyde. The 
aldehyde of the fourth sample was, however, enriched with ${ }_{13} \mathrm{C}$ when compared with the ketone. Carter et al. suggested that this may indicate the fourthMDMAsamplewas synthesized from the aldehyde piperonal rather than safrole or isosafrole, and as such the terminal methyl group was added during synthesis. From this work, Carter et al. concluded that 'isotopic content appears characteristic of a specific synthesis'. In 2004, Palhol et al.[11] investigated the discriminating power of $15 \mathrm{~N} / 14 \mathrm{Nis}$ tope ratios of $106 \mathrm{MDMAtablets} \mathrm{seized} \mathrm{by} \mathrm{police.}$ Based on $\delta 15 \mathrm{~N}$ values alone, the samples could be divided into five groups, each one separated by at least $1.16 \%$. A database was createdwhich included the $\delta 15$ Nvalues and information supplied by the police, such as physical characteristics, logo, purity, and diluents/adulterants. Application of principal components analysis to the database indicated that $\delta{ }_{15} \mathrm{~N}$ values and MDMA content were the two most important parameters of the database. Kurashima et al.[12] investigated the possibility of determining geographic origin of ephedrine by carbon and nitrogen isotope abundances and analyzed ephedrine samples from three different synthetic routes. $\delta 13 \mathrm{C}$ values allowed the discrimination of semi-synthetic ephedrine from both synthetic and natural, but the latter two could not be separated. $\delta 15 \mathrm{~N}$ analysis, however, allowed discrimination of all three routes, thus confirming what was already becoming clear in the literature: nitrogen isotope abundances allow more discriminating power than carbon alone. The applicability of stable isotope analysis was further demonstrated by a case in which heroin was seized in Australia from the Merchant Vessel Pong Su.[13] Due to unusual chromatographic impurity profiles obtained for this heroin, an investigative opinion was formed by various drug enforcement authorities that this seizure might be from a new region or new illicit process. Stable isotope analysis confirmed this opinion. In 2007, Billault et al.[14] synthesized MDMA by five synthetic pathways: reductive amination (using $\mathrm{Al} / \mathrm{Hg}$ amalgam, $\mathrm{NaBH}_{4}$, and $\mathrm{NaCNBH}_{3}$ as reducing agents), Leuckart, via theNformyIMDA, via the tosylate, and via nitrostyrene. TheMDMA and precursorswere analyzed by IRMS for $\delta 13$ Cand $\delta 15$ Nvalues. The authors reported that the reductive amination and Leuckart routes did not induce isotopic fractionation $(\delta 13 \mathrm{C}<0.6 \%)$, but the routes which proceeded via the tosylate and via nitrostyrene did induce fractionation $(\delta 13 \mathrm{C}=-1.8 \%$ and $\delta 13 \mathrm{C}=-6.0$ to $-4.4 \%$, respectively). They found that, on the basis of $\delta 13 \mathrm{C}$ values of MDMA, it was not possible to discriminate among reducing agents used for reductive amination ofMDMAbatches. As for $\delta 15 \mathrm{~N}$ values of MDMA, Billault et al. concluded that they offer no apparent discrimination according to synthetic route, but that they are strongly influenced by the nitrogen contributing precursor. They also suggested that $\delta{ }_{15} \mathrm{~N}$ values for MDMA produced via nitrostyrene, which is a four-step route starting from piperonal, were not reproducible. The authors concluded that IRMS for tracing MDMA to source is more complicated than expected, and that it might be hazardous to link MDMA samples based on $\delta{ }_{13} \mathrm{C}$ and $\delta{ }_{15} \mathrm{~N}$ values alone.

In 2008, Buchanan et al.[15] reported a study inwhichMDMA samples were synthesized in-house by three preparative methods: reductive amination using $\mathrm{Al} / \mathrm{Hg}$ amalgam, $\mathrm{NaBH}_{4}$, and $\mathrm{Pt} / \mathrm{H} 2$. The authors carefully repeated each preparative method until six batches of each were obtained (18 in total). $\mathrm{H}, \mathrm{C}$, and $\mathrm{N}$ stable isotope ratios were obtained, and Buchanan et al. reported that discrimination by synthetic route was possible using $\delta_{2} \mathrm{H}$ values alone. The effects on $\delta$ values of altering the reaction conditions have been assessed in our laboratories and will be published in due course. 
Research in this area is ongoing, and more recent publications suggest that the approach of using synthesized samples, thereby allowing known provenance samples to be analyzed, is a developing area.[15-17]

\section{IRMS of Explosives}

The use of IRMS to analyze explosive materials is based upon the knowledge that both carbon and nitrogen isotopes can provide valuable information about the explosives preparation, given that $60 \%$ of the carbon in explosives comes from the explosive itself (with the remainder from the fatty hydrocarbons and polymeric matrix)[18] and $99 \%$ of the nitrogen relates directly to the explosives and the manufacturing process.

In 2006, an excellent review paper was published detailing the state of the art with respect to the use of IRMS in forensic applications.[3] Within this paper a section was devoted to the use of IRMS to analyze energetic materials with a review starting with Nissenbaum's paper of 1975.[19] This was the first paper which described the use of IRMS to analyze the carbon isotopes inTNT manufactured in different countries. The results of this study indicated that differentiation between samples was possible and paved the way for continued research in this area. Within the 2006 review paper, details of the results of the 3-year project, funded by the UK Home Office and undertaken by the Forensic Explosives Laboratory, are published. Each year of the project is explained within the review and the conclusions from the studies suggest that IRMS can successfully differentiate between different types of explosives, between sources of chlorine in chlorate and perchlorate materials, and even between different batches from the same manufacturer.[3] In 2007, IRMS data from explosives samples was subjected to a likelihood ratio approach to determine whether or not it was possible to identify links between semtex samples.[18] The paper details the analysis of 26 samples of semtex $\mathrm{H}$, which contains $80 \%$ pentaerythritol tetranitrate (PETN) and cyclotrimethylenetrinitramine (RDX) and $20 \%$ of polymeric matrix. Four different statistical methods were evaluated and the authors concluded that the likelihood ratio approachwould allow scientists to present evidence of IRMS analysis to the court in a clear manner. The authors do, however, note that further collaboration in this area is essential to determine the true usefulness of such a technique.

Lock et al.[20] studied the preparation of RDX in order to determine if it was possible to link the starting material used in the synthesis of RDX to the prepared product using carbon and nitrogen isotope analysis. They selected five hexamine samples as the starting material and kept all other reagents and conditions constant. The samples were analyzed using NMR, FTIR, and TLC along with the isotope analysis. The first three tests were used to confirmthe identity of their products, and the IRMS data was used to determine if linkages between starting reagent and product could be made. The authors concluded that reproducible relationships could be identified between the isotope ratios $\left(\delta{ }_{13} C\right.$ and $\delta 15 \mathrm{~N}$ ) of the starting material and the corresponding RDX product.

RDX was also studied by Bernstein et al.,[21] however, these authors were concerned with investigating the use of IRMS to look at the processes of aerobic and anaerobic decomposition of RDX by microorganisms. The authors detail the use of IRMS to determine the RDX breakdown pathways in both aerobic and anaerobic conditions and show how different isotope fractionation patterns are achieved for each pathway. The study by Widory et al.[22] looks at a multi-isotope approach to the analysis of explosives. This idea has been postulated 
in the studies above but this paper details a systematic approach to the analysis of PETN, RDX, cyclotetramethylene tetranitramine (HMX), and ammonium nitrate fuel oil (ANFO) explosives. The authors conclude that this multi-isotope approach provides greater discrimination between explosive families and also that the manufacturing process along with the geographic origin of the samples influences both the nitrogen and carbon isotope values. They illustrate this with a ternary plot showing the combination of three isotopes $(\mathrm{C}, \mathrm{N}$, and $\mathrm{O})$ which clearly differentiates PETN, ANFO, TNT, and semtex, despite the semtex containing $80 \%$ PETN within its composition. The most recent paper by Quirk et al.[23] looks at the possibility of using IRMS to link a pair of radios used to initiate an improvized explosive device where one radio is intact and the other partially destroyed by the blast.This clever idea is explained clearly in the paper and the conclusions are encouraging. Four pairs of radios were studied, and in each pair one was retained as a reference while the other was detonated. The authors explain that the fragmentation of the test radios was severe, but where greater than two identifiable fragments were recovered from the blast, it was possible to determine an association between the pre- and post-blast radios using carbon and hydrogen isotope analysis.

More recent research has concentrated on an analysis of peroxide based explosives such as triacetonetriperoxide (TATP),[24] aswell as attempts to source and discriminate between explosives such as ammonium nitrate.[25]

\section{Human Provenancing}

The use of stable isotopes as a tool in human identification is an emerging application of IRMS that is rapidly gaining momentum, acceptance, and credibility within the forensic community. While individual identifications cannot be made, case information may be obtained that can focus an investigation or provide information about an individual's recent geographical whereabouts. This information may be particularly useful in cases where DNA is not available, if DNA reference standards are not available, orwhen the geographicalwhereabouts of an individual are pertinent to a case, e.g. terrorism suspects.

Samples suitable for stable isotope profiling using IRMS include hair, nail, bone, and teeth, although clearly when the technique is applied to living human beings, non-invasive samples (hair and nail) are favoured.[26] Isotopic profiles obtained from human samples are a reflection of food and water intake. In particular, ${ }_{13} \mathrm{C}$ and $15 \mathrm{Nare}$ reflective of food consumedwhile $2 \mathrm{H}$ reflects water intake (as does $18 \mathrm{O}$, although to a limited extent). Abundances of these isotopes, therefore, provide an indication of the dietary lifestyle and geographical origin of an individual. Following on from some of the fundamental studies of Ehleringer et al.[27] investigating the links between stable isotope signatures in hair of US residents and geographic provenance, Fraser et al.[26,28] developed isotope profiling methods for hair and nails. They conducted studies yielding information about the intra- and inter-variability of individuals within a geographical area[26] and have demonstrated that information regarding recent geographical whereabouts can be obtained from $2 \mathrm{H}$ isotope profiling of hair and nail samples.[28]

Meier-Augenstein and Fraser[29] reported the first use of isotope analysis in aiding the identification of an unknown victim.

They examined hair and nail samples from a dismembered body. Using data obtained from their previous longitudinal study,[27] as well as data from the Global Network for Isotopes in Precipitation, they were able to provide sufficient information about the likely geographical origin of the victim and approximate time 
period of entry into the country. This allowed investigators justification for DNA analysis that resulted in identification of the

victim.

Furthering the use of isotope profiling in human provenancing and identification will require more extensive geographical mapping of isotope profiles. In addition, further studies are required to determine the variability of isotope profiles from individuals within a geographical area. Nevertheless, this application of IRMS offers a powerful tool that, with further study, will be increasingly valuable in forensic investigations.

\section{Wildlife Samples}

Various studies have been carried out in the recent past investigating stable isotopic ratios in plant and animal species. The issues under investigation are two-fold: first, is it possible to differentiate between animals and plants bred in captivity versus those which originate from wild habitats;[30] second, is it possible to make use of stable isotope ratio analysis to inform of the movement of animals and the potential location of products derived from animals? These issues are highly complex and research has focussed on gaining an understanding of the distribution and residence time of the various isotopes in different body tissue samples.[31,32]

\section{The Implications of Stable Isotope Ratio Analysis in Forensic Science}

It is clear from the above that a wide range of materials are amenable to analysis by IRMS and that methodologies for specific applications are developing steadily. It is also obvious that IRMS has enormous potential for forensic applications, but how are we to assess its true value in this context? Such an evaluation must take into account not only the analytical value of IRMS but also the contribution and potential risks it presents in a legal context. Few legal systems (if any) have systematic mechanisms for assessment of the benefits and risks presented by new technologies, and many allow such applications to be introduced in an almost ad hoc manner. If we consider the use of IRMS in relation to a criminal inquiry, scientists are intermediaries in this process, which is controlled generally by the police (in common law jurisdictions) and ultimately the courts. There is extensive published[33] evidence that demonstrates that most police officers have very little knowledge of forensic science, and this will be particularly the case for new or emerging techniques. Lack of scientific knowledge by the police and courts presents a significant problem in the introduction of new methodologies. The great potential that IRMS promises invites comparison with the last major technical breakthrough in forensic science: DNA profiling. The early years of DNA profiling were characterized by the resistance of legal systems to its use, and lack of standards for analysis and interpretation, which led to 'DNA wars' in courts, scientific journals, and in the press. There were also miscarriages of justice. Many of the issues were not resolved until the introduction of completely new technology for DNA profiling based on polymerase chain reaction, more than a decade later.An essential element of the current development of IRMS, therefore, is the development of international standards of analysis and accredited protocols. This will require extensive cooperation and communication between institutions, as preparation for legal 'acceptance' of the technique. DNA profiling is a very powerful technique for the identification of individuals, but its current significance in criminal justice terms required the political will to introduce new legislation and invest financially in its development (especially databases) by governments. There can be little doubt that IRMS has considerable potential 
to answer several of the central questions in a criminal inquiry, such as the provenance of humans or the geographical origins of illicit drugs. It is also likely to be of great value in non-criminal investigations such as the provenance of food and beverages. The contribution that IRMS will make to such inquiries will depend on factors largely outside the control of scientists, primarily the particular legal jurisdiction inwhich it is applied and other highly influential external factors such as the political and economic climate. As a potential tool for the provenance of humans, it is essential that we avoid the mistakes made in the introduction of some DNA databases by encouraging informed public debate, including the ethical issues that this raises, before any systematic use of IRMS.

\section{Conclusions}

The development of new analytical techniques in chemistry is a relatively rare occurrence these days; rather, the application of existing technology to solve specific problems is more commonly the case. The emerging use and functionality of isotope ratio mass spectrometry in forensic analysis now covers a range of evidence types including illicit drugs, explosives and samples of human or animal origins. IRMS has also begun to be used for other forensic science-related exhibits such as plastic bags,[34] paint,[35] matches,[36] and documents,[37] and its influence on the field of forensic chemistry is set to continue into the future. One of the ongoing research questions related to IRMS data is, of course, its evidentiary or investigative value, and the analysis of known provenance samples will continue to be required in order to address this issue.

\section{References}

[1] J.T. Brenna,T.N. Corso, H. J.Tobias, R. J. Caimi, Mass Spectrom. Rev. 1997, 16, 227. doi:10.1002/(SICI)1098-2787(1997)16:5<227::AIDMAS1> 3.0.CO;2-J

[2] W. Meier-Augenstein, J. Chromatogr. A 1999, 842, 351. doi:10.1016/ S0021-9673(98)01057-7

[3] S. Benson, C. Lennard, P. Maynard, C. Roux, Forensic Sci. Int. 2006, 157, 1. doi:10.1016/J.FORSCIINT.2005.03.012

[4] E. K. Shibuya, J. E. S. Sarkis, O. N. Neto, M. Z. Moreira, R. L. Victoria, Forensic Sci. Int. 2006, 160, 35. doi:10.1016/J.FORSCIINT. 2005.08.011

[5] M. Desage, R. Guilluy, J. L. Brazier, H. Chaudron, J. Girard, H. Cherpin, J. Jumeau, Anal. Chim. Acta 1991, 247, 249. doi:10.1016/ S0003-2670(00)83820-9

[6] F. Mas, B. Beemsterboer, A. C. Veltkamp, A. M. A. Verweij, Forensic Sci. Int. 1995, 71, 225. doi:10.1016/0379-0738(94)01670-4

[7] F. Besacier, H. Chaudron-Thozet, M. Rousseau-Tsangaris, J. Girard, A. Lamotte, Forensic Sci. Int. 1997, 85, 113. doi:10.1016/S03790738(96)02086-5

[8] J. R. Ehleringer, J. F. Casale, M. J. Lott, V. L. Ford, Nature 2000, 408, 311. doi: $10.1038 / 35042680$

[9] J. F. Carter, E. L.Titterton, M. Murray, R. Sleeman, Analyst 2002, 127, 830. doi:10.1039/B201496N

[10] J. F. Carter, E. L. Titterton, H. Grant, R. Sleeman, Chem. Commun. 2002, 21, 2590. doi:10.1039/B207775B

[11] F. Palhol, C. Lamoureux, M. Chabrillat, N. Naulet, Anal. Chim. Acta 2004, 510, 1. doi:10.1016/J.ACA.2003.12.069

[12] N.Kurashima,Y. Makino, S. Sekita,Y. Urano,T. Nagano,Anal. Chem. 2004, 76, 4233. doi:10.1021/AC035417C

[13] J. Casale, E. Casale, M. Collins, D. Morello, S. Cathapermal, S. Panicker, J. Forensic Sci. 2006, 51, 603. doi:10.1111/J.15564029.2006.00123.X

[14] I. Billault, F. Courant, L. Pasquereau, S. Derrien, R. J. Robins, N. Naulet, Anal. Chim. Acta 2007, 593, 20. doi:10.1016/J.ACA. 2007.04.039

[15] H. A. S. Buchanan, N. Nic Daéid, W. Meier-Augenstein, H. F. Kemp, W. J. Kerr, M. Middleditch, Anal. Chem. 2008, 80, 3350. doi:10.1021/AC702559S

[16] A. de Korompay, J. C. Hill, J. F. Carter, N. Nic Daéid, R. Sleeman, J. Chromatogr. A 2008, 1178, 1. doi:10.1016/J.CHROMA.2007.11.054 
[17] W. Meier-Augenstein, N. Nic Daéid, Forensic Sci. Int. 2008, 174, 259. doi:10.1016/J.FORSCIINT.2007.05.006

[18] G. Pierrini, S. Doyle, C. Champod, F. Taroni, D. Wakelin,

C. Lock, Forensic Sci. Int. 2007, 167, 43. doi:10.1016/J.FORSCIINT.

2006.06.013

[19] A. Nissenbaum, J. Forensic Sci. 1975, 20, 455.

[20] C. M. Lock,W. Meier-Augenstein, Forensic Sci. Int. 2008, 179, 157.

doi:10.1016/J.FORSCIINT.2008.05.015

[21] A. Bernstein, Z. Ronen, E.Adar, R. Nativ, H. Lowag,W. Stichler, R.U.

Meckenstock, Environ. Sci. Technol. 2008, 42, 7772. doi:10.1021/

ES8005942

[22] D.Widory, J. J. Minet, M. Barbe-Leborgne, Sci. Justice 2009, 49, 62. doi:10.1016/J.SCIJUS.2008.11.001

[23] A. T. Quirk, J. M. Bellerby, J. F. Carter, F. A. Thomas, J. C. Hill, Sci. Justice 2009, 49, 87. doi:10.1016/J.SCIJUS.2009.02.009

[24] S. J. Benson, C. J. Lennard, P. Maynard, D. M. Hill, A. S.

Andrew, C. Roux, Sci. Justice 2009, 49, 81. doi:10.1016/J.SCIJUS.

2009.03.004

[25] S. J. Benson, C. J. Lennard, P. Maynard, D. M. Hill, A. S. Andrew, C. Roux, Sci. Justice 2009, 49, 73. doi:10.1016/J.SCIJUS.2009.04.005

Stable Isotope Ratio Analysis in Forensic Chemistry 7

[26] I. Fraser, W. Meier-Augenstein, R. M. Kalin, Rapid Commun. Mass Spectrom. 2006, 20, 1109. doi:10.1002/RCM.2424

[27] I. Fraser, W. Meier-Augenstein, Rapid Commun. Mass Spectrom. 2007, 21, 3279. doi:10.1002/RCM.3209

[28] J. R. Ehleringer, G. J. Bowen, L. A. Chesson, A. G. West, D. W.

Podlesak, T. E. Cerling, Proc. Natl. Acad. Sci. USA 2008, 105, 2788. doi:10.1073/PNAS. 0712228105

[29] W. Meier-Augenstein, I. Fraser, Sci. Justice 2008, 48, 153.

doi:10.1016/J.SCIJUS.2007.10.010

[30] A. Kelly, R. Thompson, J. Newton, Sci. Justice 2008, 48, 67.

doi:10.1016/J.SCIJUS.2007.09.012

[31] G. J. Bowen, L. I. Wassenaar, K. A. Hobson, Oecologia 2005, 143,

337. doi:10.1007/S00442-004-1813-Y

[32] D. W. Podlesak, A. Torregrossa, J. R. Ehleringer, M. D. Dearing,

B. H. Passey, T. E. Cerling, Geochim. Cosmochim. Acta 2008, 72,

19. doi:10.1016/J.GCA.2007.10.003

[33] J. G. Fraser, in Handbook of Criminal Investigation (Eds T. Newburn, T. Williamson, A. Wright) 2007, Ch. 15, pp. 381-402 (Willian Publishing: Devon).

[34] E. Taylor, J. F. Carter, J. C. Hill, C. Morton, N. Nic Daéid, R. Sleeman, Forensic Sci. Int. 2008, 177, 214. doi:10.1016/ J.FORSCIINT.2008.01.006

[35] N. Farmer,W. Meier-Augenstein, D. Lucy, Sci. Justice 2009, 49, 114. doi:10.1016/J.SCIJUS.2009.02.003

[36] N. Farmer, J. Curran, D. Lucy, N. Nic Daéid, W. Meier-Augenstein, Sci. Justice 2009, 49, 107. doi:10.1016/J.SCIJUS.2009.03.007

[37] A. van Es, J. de Koeijer, G. van der Peijl, Sci. Justice 2009, 49, 120. doi:10.1016/J.SCIJUS.2009.03.006\# 